\title{
DIÁLOGOS POSSÍVEIS: HISTÓRIA E JORNALISMO
}

\author{
Aline Sajnaj Ferreira ${ }^{1}$ \\ Clóvis Gruner ${ }^{2}$
}

\section{Resumo}

Este artigo faz uma reflexão sobre os diálogos que se estabelecem entre as práticas de jornalistas e historiadores. Fundamentado na concepção de que, além das semelhanças e diferenças, há influências de uma prática sobre a outra, o artigo apresenta considerações sobre Jornalismo e História, inclusive como formações discursivas, e discorre a respeito das práticas e abordagens semelhantes. Embasado no jogo de Foucault do verdadeiro e do falso, o artigo também avalia a relação com a verdade. Trata-se de uma abordagem teórica, baseada em bibliografias.

Palavras-chave: Comunicação, jornalismo, história, interdisciplinaridade.

\begin{abstract}
The aim of this article is to analyze the relationship between the practices of journalists and historians. It is based on the conception that, besides similarities and differences, there are influences from one practice to the other. The article presents considerations on Journalism and History, taken as discursive formations, and discuss similarities between the practices of those two fields. It is based on the conception of true and false in Foucault. This article evaluates the relationship of those two fields and truth. In order to do so, we use theoretical and biographical approach.
\end{abstract}

Keywords: Communication, journalism, history, interdisciplinarity.

\section{Introdução}

Com a ascensão de livros com temática histórica escritos por jornalistas, torna-se necessária uma análise a respeito dessas duas práticas, já que acabam sendo alvos de comparações. Durante a pesquisa que resultou na monografia Jornalismo e História: fronteiras e semelhanças, uma analogia entre as duas práticas ${ }^{3}$, foi observado que ambas as atuações apresentam semelhanças, diferenças e influências de uma prática sobre a outra, além de certo conflito a respeito do trabalho em profundidade feito na História em contraposição ao caráter de efemeridade das notícias no campo jornalístico.

As comparações direcionadas às duas profissões atingem não apenas as "ferramentas" utilizadas por ambas, suas origens e abordagens, mas também seus respectivos papéis e funções

\footnotetext{
${ }^{1}$ Jornalista (Universidade Positivo), especialista em História Cultural (Universidade Tuiuti do Paraná).

${ }^{2}$ Doutor em História (Universidade Federal do Paraná), professor do Programa de Pós-graduação em História da mesma instituição.

${ }^{3}$ Monografia apresentada em 2011 no curso de Pós-graduação de História Cultural da Universidade Tuiuti do Paraná, sob a orientação do professor Clóvis Gruner.
} 
na sociedade. No que diz respeito às práticas, tanto no jornalismo ${ }^{4}$ como na história ${ }^{5}$, é notável a presença da interpessoalidade em relação às fontes, pois nas duas áreas comparecem a escolha de personagens e a construção de situações, o que se relaciona com a verdade, um dos pontos principais em torno da discussão do fazer jornalístico e do histórico.

A entrevista, a observação participante, o uso da memória, da história oral e o tempo presente fazem parte de ambas as atuações, visto que estas apresentam a relação pesquisadorfonte. A memória, por sua vez, é definida de inúmeras formas. No entanto, o apreço, por parte de jornalistas e historiadores, em relação a esta deve ser maior devido às discussões que abordam sua validade e credibilidade. A história oral, por sua vez, está interligada à memória, uma vez que se nutre de lembranças individuais.

\section{Jornalismo e História como formações discursivas}

Toda linguagem é dialógica, isso quer dizer que há uma relação entre discursos (os sentidos do que se fala) e entre sujeitos (o discurso só pode existir se houver sujeitos que façam o intermédio). Essa intermediação é chamada de intersubjetividade e, geralmente, como afirma Marcia Benetti (2007), nos dá a impressão - ingênua - de que aquilo que está sendo dito é

\footnotetext{
${ }^{4}$ O jornalismo manifestou-se na Europa em pleno século XVIII com a Revolução Francesa. Nilson Lage (2000) argumenta que "a notícia, antes restrita e controlada pelo Estado e pela Igreja, tornou-se bem de consumo essencial" (LAGE, 2000, p.8). Em consequência, e com a expansão do capitalismo, a imprensa passou a fazer parte do sistema empresarial, dando encadeamento à exploração comercial dos recursos de comunicação. A partir de então, as empresas jornalísticas passaram a se caracterizar pela obtenção de lucros devido à venda de espaços comerciais para a sustentação dos veículos de comunicação na nova sociedade, a capitalista. A partir do século XX, a Comunicação (de "massa") tornou-se tão significativa no mundo inteiro, de modo que acabou modificando e substituindo outras instituições ou espaços sociais (LAGE, 2000). No início, a atividade do jornalista voltava-se ao interesse público, desenvolvendo assim, através das discussões nas quais todos tinham acesso, o que seria a opinião pública. Tal prática pode ser comparada à esfera pública. Idealizada pela classe burguesa, estimulava conversas, diálogos e discussões. Todos podiam participar e trocar conhecimentos e experiências, o que acarretou em diversas transformações, como a responsabilidade do Estado pelo campo público, o que até então cabia ao senhor feudal.

${ }^{5}$ No final do século XX, a prática dos historiadores sofreu algumas mudanças que acarretaram em uma forma de diálogo da História com outras disciplinas. Sem deixar de lado o grande valor de algumas questões, como a ordem estrutural, tratamentos estatísticos, entre outras, a terceira geração dos Annales, na França - uma tendência que passou a existir em 1929 com a publicação de uma revista acadêmica homônima, tendo Marc Bloch e Lucien Febvre como fundadores - realizou um deslocamento com uma proposta de novas abordagens (LE GOFF, 1998). A Nova História apontava duas direções diferenciadas. Não tendo mais como ponto central a política, a história começa então a abordar diversos outros temas. É a "história total" defendida por Fernand Braudel. Da década de 1970 em diante, ocorre a popularização da Nova História devido às grandes mudanças e transformações sociais que aconteciam em todos os lugares do mundo. "A história nova ampliou o campo do documento histórico; ela substituiu a história de Langlois e Seignobos, fundada essencialmente nos textos, no documento escrito, por uma história baseada numa multiplicidade de documentos: escritos de todos os tipos, documentos figurados, produtos de escavações arqueológicas, documentos orais, etc.” (LE GOFF, 1998, p.28).
} 
natural, óbvio e evidente. Isso acontece porque discursos são carregados de ideologia ${ }^{6}$ e, quanto mais naturalizada for, maior é a impressão de literalidade daquilo que se ouve ou lê.

Mas isso não acontece, já que o discurso depende dos sujeitos para existir. Portanto, ele é produzido não apenas por quem fala, mas também por quem lê. Segundo Benetti (2007), é exatamente pelo fato de o discurso ser pleno de possibilidades de interpretações que pretensões de relatar fielmente os fatos são falhas. Isso ocorre porque há no discurso uma relação entre a linguagem e exterioridade do mesmo. Quer dizer que o sujeito que pronuncia tem a sua própria cultura e ideologia. Nessa lógica, ao mesmo tempo em que leitor e texto se aproximam, também podem se afastar na medida em que a historicidade de ambos emerge no processo de leitura.

Benetti (2007) afirma ainda que todo texto possui duas camadas: a primeira, mais visível, é denominada discursiva; já a segunda, evidente apenas quando o método da análise de discurso é feita, é a ideológica. O primeiro passo para a análise discursiva é a identificação das formações discursivas (FDs) ${ }^{7}$, que podem ser compreendidas "como aquilo que pode ser dito, em oposição ao que não pode ser dito”.

Partimos agora para a hipótese inicial de Foucault, no seu livro A Ordem do Discurso (2009), de uma regulamentação no processo de produção de discursos nas sociedades. O autor salienta procedimentos de controle e delimitação dos discursos: a interdição, considerado o mais evidente e familiar, que se refere ao fato de não poder dizer tudo em qualquer circunstância, o que revela a ligação com o poder; a razão e a loucura, que diz respeito ao louco, aquele discurso que não circula como outros, considerado sem importância. O último procedimento listado por Foucault é a vontade de verdade, cuja discussão gira em torno do verdadeiro e do falso, que estão envolvidos em sistemas de instituições que impõem e reconduzem.

Em meio à complexidade ${ }^{8}$ na qual as questões dos discursos estão envolvidas, e, consequentemente, o trabalho dos jornalistas e historiadores, é importante salientar que um

\footnotetext{
${ }^{6}$ Atenta ao fato de que a autora Márcia Benetti utiliza muito o termo "ideologia" e que o conceito para Foucault é um tanto problemático, justificamos a proximidade dos autores nessa parte do trabalho baseado justamente nas relações entre a história e o jornalismo, tema central do presente trabalho. Assim como as duas práticas não têm abordagens e características idênticas, porém, podem interagir, também podemos pensar dessa forma a proximidade de Benetti e Foucault.

${ }^{7} \mathrm{O}$ discurso jornalístico, por exemplo, é considerado polifônico - já que por ele circulam diversas vozes, como: as fontes, o jornalista-indivíduo que assina o texto, e o jornalista-instituição (veículo de comunicação). Ao mapear as vozes do discurso e refletir sobre as posições do sujeito ocupadas por indivíduos distintos, pode-se perceber que o texto pode ter caráter polifônico ou monofônico (BENETTI, 2007).

${ }^{8}$ Foucault, em sua aula inaugural no Collège de France (dezembro de 1970), delineia três direções que o trabalho da elaboração teórica pode seguir. São elas: princípio de inversão, onde acreditamos reconhecer as fontes dos discursos, assim como sua expansão e continuidade; de descontinuidade, que se baseia na ideia de que não há discursos contínuos, ao contrário, eles são práticas que, muitas vezes, se excluem; de especificidade, no qual é preciso considerar o discurso como "uma violência que fazemos às coisas", ou seja, o discurso não é um jogo de
} 
acontecimento discursivo "trata-se de cesuras que rompem o instante e dispersam o sujeito em uma pluralidade de posições e de funções possíveis" (FOUCAULT, 2009. p. 58).

Jornalismo e história, devido às suas práticas, obtêm próprias identidades e podem ser vistos como espaços plurais, dialogando com outras disciplinas e campos. É por esta razão que vamos procurar enxergá-los como "formações discursivas". Esse conceito de Foucault está relacionado com a problemática do sujeito, no que diz respeito ao aspecto linguístico e sóciohistórico.

Ao discutir o enunciado e propondo uma concepção de formação discursiva, o autor analisa as condições de possibilidades dos discursos. A partir daí, Foucault se utiliza de quatro hipóteses, nas quais são analisadas as relações entre os variados enunciados. A primeira aborda o enunciado e o objeto como sendo um conjunto. Entretanto, ele alerta que um mesmo objeto pode se modificar no tempo ${ }^{9}$. Isso quer dizer que a construção de um discurso se dá devido a definições que aparecem com o tempo. A segunda inicia com a ideia de que um conhecimento, a medicina, por exemplo, se caracteriza por estilos da enunciação. Nessa hipótese, há modificações num discurso a partir das alterações que se depositam nos discursos médicos ${ }^{10}$.

A terceira diz respeito à relação entre os conceitos permanentes e coerentes e os enunciados: conceito de juízo como forma geral e normativa de qualquer frase, de sujeito e predicativo sendo da categoria geral de nome, o de palavra como representação, entre outros. Porém, há uma grande variedade de novos $\operatorname{conceitos}^{11}$. Já a quarta e última hipótese aponta para

significações; e a exterioridade, que se refere às suas condições externas de possibilidades. Foucault fala também dos procedimentos internos do discurso, que se submete a outra dimensão, ou seja, do acontecimento e do acaso: comentário, caracterizado pelo autor como aquele que contém um "desnivelamento entre os discursos", aqueles que são ditos e permanecem ditos, como discursos religiosos ou jurídicos, por exemplo. O seguinte é o autor, atribuído ao princípio de agrupamento do discurso no que diz respeito a unidade, significações, coerência e origem. Enfim, Foucault aborda as disciplinas, aquilo que demanda a construção de outros novos enunciados. Elas se distinguem pelo "domínio de objetos, conjunto de métodos, um corpus de proposições consideradas verdadeiras, um jogo de regras e de definições, de técnicas e de instrumentos" (FOUCAULT, 2009, p. 30). Na sua ordem do discurso, Foucault trata da imposição de regras aos sujeitos dos discursos. A primeira delas é o ritual, que cumpre o papel de definir a qualificação que os indivíduos que falam devem ter, seus gestos, comportamento, circunstâncias e todo o conjunto de signos que acompanham o discurso. "Os discursos religiosos, judiciários e políticos não podem ser dissociados dessa prática de um ritual que determina para os sujeitos que falam, ao mesmo tempo, propriedades singulares e papéis preestabelecidos" (FOUCAULT, 2009 p. 38). Há também as doutrinas, que fazem parte da "sociedade do discurso", na qual os indivíduos que falam estão ligados a determinados tipos de enunciação. E, por último, a apropriação social dos discursos, sistema no qual o espaço em que os indivíduos podem ter acesso a diversos discursos.

${ }^{9}$ Para explicar essa questão, Foucault utiliza o estudo da loucura para exemplificar: "não se trata das mesmas doenças, não se trata dos mesmos loucos" (FOUCAULT, 2002 p. 36).

${ }^{10}$ Dentre algumas dessas alterações, Foucault aponta para o fato de que o "[...] médico, pouco a pouco, deixou de ser o lugar de registro e de interpretação da informação e, porque, ao lado dele, fora dele, constituíram-se massas documentárias, instrumentos de correlação e técnicas de análise que ele tem, certamente, que utilizar, mas que modificam, em relação ao doente, sua posição de sujeito observante" (FOUCAULT, 2002, p.38).

${ }^{11}$ Sendo assim, a busca não é mais pela "arquitetura de conceitos suficientemente gerais e abstratos para explicar todos os outros e introduzi-los no mesmo edifício dedutivo", mas sim pela análise do "jogo de seus aparecimentos e de sua dispersão" (FOUCAULT, 2002, p.40). 
uma identidade e a persistência dos temas. Uma temática que se articula devido aos diferenciados conceitos, análises e objetos. São justamente tais questões discutidas nas quatro hipóteses que se origina o conceito de formação discursiva. Os discursos, para Foucault, são formados por elementos dispersos.

\begin{abstract}
No caso em que se puder descrever, entre um certo número de enunciados, semelhante sistema de dispersão, e no caso em que entre os objetos, os tipos de enunciação, os conceitos, as escolhas temáticas, se puder definir uma regularidade (uma ordem, correlações, posições e funcionamentos, transformações), diremos, por convenção, que se trata de uma formação discursiva (FOUCAULT, 2002 p.43).
\end{abstract}

Utilizaremos a discussão sobre a "dispersão" para adentrar na questão das práticas dos jornalistas e dos historiadores. Pois tanto o jornalismo (com a diversidade de assuntos abordados num veículo de comunicação, na pluralidade de enunciações, segmentação profissional, além da maneira com que os veículos jornalísticos se apresentam no espaço social a que pertencem) como a história (as amplas apreensões das pesquisas históricas, a dispersão temporal dos objetos históricos e na diversidade de correntes e metodologias) podem ser vistos como unidades dispersas, que se encontram sempre em transformação.

Essas variações são responsáveis por constituir relações, seja de oposição, de semelhança ou até mesmo relações complementares, como afirma Foucault (2002), quando diz que é possível descrever entre diversos discursos as relações de delimitação mútua em cada um, dando origem às marcas características de sua singularidade pela diferenciação de seus domínios. É justamente esse emaranhado de relações que faz com que as práticas jornalísticas e históricas adquiram suas identidades próprias.

\title{
Relação com a verdade no jornalismo e na história
}

Visto que ambas as práticas têm de se relacionar com a verdade pelo fato de trabalhar com pessoas, surge a pergunta: como é essa relação? Tendo como base o jogo do verdadeiro e do falso de Foucault (2002), é possível questionar: em que condições e de que forma de racionalidade o sujeito pode dizer a verdade sobre si mesmo, já que ele é um objeto histórico? 
Ontologias históricas ${ }^{12}$, delineadas por Foucault (2002), mostram que a verdade é efeito gerado por práticas que produzem práticas. Para Foucault, tudo é construído, nada é natural. O sujeito é constituído por tramas históricas de poder.

\begin{abstract}
A verdade, para Foucault, é o conjunto de regimes segundo os quais se distingue o verdadeiro e o falso e se atribui ao verdadeiro efeitos de poder. [...] A verdade é uma máscara discursiva construída para a prática da beligerância, impossível de ser arrancada: atrás de uma máscara, outra, e outra, e outra... Ela é assumida como construída em relações concretas por agentes históricos e particulares, sem nenhuma ambição de universalidade (REIS, 2003, p.168-9).
\end{abstract}

Mostrando a aproximação do inquisidor e do antropólogo, Carlo Ginzburg (2007) trata das descrições detalhadas dos cultos e ritos das feiticeiras, contendo gestos, silêncios, entre outras reações que, no caso dos atos inquisitoriais, poderiam indiciar a "verdade" do inquisidor. O impulso dos inquisidores no sentido de buscar a verdade (a verdade deles) nos legou uma documentação rica, decerto, mas distorcida pelas pressões físicas e psicológicas que caracterizavam os processos de feitiçaria (GINZBURG, 2007 p. 284).

Ginzburg afirma que cada discurso é feito de acordo com os ideais de quem o faz, não imune de sofrer influências de variantes, como o lugar social. No caso do inquisidor versus réu, os interrogatórios e os documentos escritos que descrevem o ato eram feitos de acordo com a visão dos inquisidores.

\footnotetext{
Não existem textos neutros: mesmo um inventário notarial implica um código, que temos de decifrar. [...] O confronto entre inquisidores e antropólogos resulta, também desse ponto de vista, esclarecedor. Já vimos que uma realidade cultural contraditória pode surgir inclusive de textos pesadamente controlados, como os processos inquisitoriais. A mesma conclusão pode ser estendida aos textos das relações etnográficas. [...] o que está em jogo aqui seriam apenas vozes diferentes no interior do mesmo texto, e não realidades diferentes (GINZBURG, 2007 p. 288).
}

Há também outro ponto que está envolvido tanto com o trabalho do historiador, como com o do jornalista, que são as representações de Roger Chartier (2007). Este, por sua vez, defende que são as práticas que organizam a sociedade e o papel dos pesquisadores, por sua vez, é ler as representações da realidade. Ao ler um texto, mesmo que o leiamos a partir de

\footnotetext{
${ }^{12}$ Em relação às suas obras e os estudos feitos sobre elas, Foucault (2002) delineia três ontologias históricas, baseadas na relação que as obras têm com a verdade. A primeira trata da nossa relação com a verdade, responsável por compor sujeitos de conhecimento; a segunda é a relação de nós mesmos com o poder, sobre as ações para com os outros; já a terceira e última baseia-se na nossa relação com a ética.
} 
nossa opinião, não rompemos com o autor, pois lemos com base na interpretação de quem o escreveu. Quando escrevemos, o fazemos com predeterminantes a serem lidas. Segundo o autor, a representação ajuda a formar grupos e pode ainda ser objeto de poder. O que é representado é interpretado. Representar, então, é dar forma, dar sentido.

\section{Interpretações}

Como construir história a partir da oralidade? Para Thompson (2002), tal procedimento proporciona novas possibilidades. Entretanto, o fato de escolher a frase mais expressiva ou dar forma a uma exposição, por exemplo, são meramente semelhantes quando as fontes são documentos escritos. Um ponto que merece atenção é o fato de que quando os textos tornamse disponíveis, possibilitam novas interpretações vindas dos leitores.

Partindo da individualidade de cada um, a interpretação é capaz de criar relações, sentimentos e emoções do leitor ${ }^{13}$. Se é correto afirmar que uma grande quantidade de leitores se identificaram com os mesmos personagens, o mesmo não podemos dizer em relação à interpretação e o procedimento de identificação de cada um. Ao falar em novas interpretações, identificação e efeitos emocionais voltamos no quesito em relação ao lugar social de quem lê e escreve. Sendo assim, o pesquisador, ao produzir um discurso, dentro dos preceitos de sua prática, o fará de acordo com seus ideais. E o público-alvo, por sua vez, receberá o material também conforme seu lugar social, seu ponto de vista, suas identificações, etc.

Sobre essas abstrações nas envolturas dos discursos, Chartier (2007) destaca que a produção dos textos, livros ou quaisquer outros materiais escritos, é um procedimento complexo que engloba diversos fatores, tais como o ato e o momento da escrita e as técnicas e intervenções de copistas, livreiros, editores, entre outros.

\section{Práticas e abordagens semelhantes: observação participante e memória}

No surgimento da moderna Antropologia nasce também o contato direto com o grupo a ser analisado, cujo procedimento até então era baseado em relatos. Eram informações indiretas, fornecidas por cartas de viajantes, missionários e colonizadores. O trabalho de "ir a campo", como sugere Rafael José dos Santos (2005, p. 37), é denominado etnografia, uma forma de "mapear as etnias". Participando da vida do Outro e conhecendo a cultura de diferentes povos

\footnotetext{
${ }^{13}$ É o que Lyn Hunt (2009) mostra ao contar como os leitores se identificaram com um romance de Rousseau, Júlia ou A nova Heloísa ${ }^{13}$, que conta a história do amor abstruso de Heloísa e Abelardo, aluna e professor. Impossibilitados de ficarem juntos, o casal troca cartas íntimas, cartas estas que cativaram os leitores, devido à intensa identificação com os personagens.
} 
que eram vistos como inferiores, os antropólogos perceberam a diferença no modo como eles eram relatados. "Este trabalho de campo longe de ser visto como um modo de conhecimento secundário servindo para ilustrar uma tese, é considerado como a própria fonte de pesquisa" (LEPLANTINE, 1988 p.76).

A etnografia só passa a existir no início do século XX, quando o pesquisador coloca em prática o trabalho de observação direta. A técnica de observação participante, utilizada por pesquisadores, que permite a convivência entre o pesquisador e as fontes, possibilita o aprofundamento na pesquisa de campo, como a captação do comportamento e gestos dos entrevistados.

Ciente deste contato direto e pensando nas práticas executadas pelo jornalismo e pela história, surge a questão: é possível lembrar os acontecimentos tais como ocorreram? Para tratarmos da memória, veremos as abordagens de autores presentes no estudo de Ecléa Bosi (1994), no seu livro Memória e Sociedade. O pressuposto de Henri Bergson, autor que estuda o mecanismo da memória no corpo, é de que é possível guardar os acontecimentos na sua integridade. O sonho, por sua vez, é o momento no qual a lembrança se manifesta da forma mais pura. As lembranças acontecem por meio dos filtros do presente. Porém, a memória está em estado bruto e os estados psíquicos estão conservados e, portanto, passíveis de estímulos capazes de permitir alternativas de escolhas. Já para Bergson, a memória está sempre presente em estado bruto.

Em contraposição a Bergson, Maurice Halbwachs afirma que a memória é coletiva, ou seja: os grupos, tais como a família, a religião, os sindicatos, partidos políticos, entre outros, têm determinados elementos que são lembrados para criar um vínculo de que podemos chamar de identidade. Já William Stern afirma que as percepções passam por um “período latente”, ou seja, um momento em que elas se apagam da consciência. Esses apagamentos duram até o instante em que determinados motivos fazem com que os fatos apareçam. A existência desses períodos inconscientes é denominada “fundo ininterrupto". O que acontece é uma reanimação de imagens que foram recebidas em períodos passados.

Ao trabalhar a memória, Charles Bartlett utiliza o conceito de "convencionalização", cuja definição pode ser entendida como o processo pelo qual as imagens e ideias percorrem, quando recebidas de fora, em um determinado grupo, tais como os indígenas. Essas imagens e ideias assumem uma forma de expressão que se ajustam às técnicas e convenções verbais estabelecidas há longo tempo. 
A memória então é formada coletivamente. Isso quer dizer que nada pode ser analisado ou lembrado isoladamente, mas sim como um todo, primeiramente para que depois se entendam as partes. É o que ocorre com o "enorme peixe" de Rudolf Otto ${ }^{14}$. Uma vez entendido que os fatos estão interligados, a memória, por sua vez, funciona como as sensações numinosas, capazes de criar e construir fatos de acordo com os aspectos vividos no presente. Cabe então aos historiadores e jornalistas levarem em consideração os aspectos do momento atual, assim como a formação das sensações numinosas, que são sentidas conforme o contexto e a época vivida.

\section{História oral}

Utilizada como instrumento de pesquisa e fonte documental ${ }^{15}$, a história oral está presente em diversas disciplinas das ciências humanas, como afirma Verena Alberti (2005). Complementando, Paul Thompson (1992), assegura que o método é utilizado, por historiadores, mas também por outros estudiosos, como sociólogos, antropólogos e jornalistas. E para salientar as aproximações das práticas, a declaração de Alberti pode ser a base.

Se podemos arriscar uma rápida definição, diríamos que a história oral é um método de pesquisa [...] que privilegia a realização de entrevista com pessoas que participaram de, ou testemunharam acontecimentos, conjunturas, visões de mundo, como forma de se aproximar do objeto de estudo [...] Trata-se de estudar acontecimentos históricos, instituições, grupos sociais, categorias profissionais, movimentos, conjunturas etc. à luz de depoimentos de pessoas que deles participaram ou os testemunharam (ALBERTI, 2005, p.18).

O uso da história oral como forma de trabalho é crescente, porém, as dúvidas acerca de sua credibilidade são grandes. As questões que são colocadas em pautas são: o entrevistado pode esquecer, omitir ou até mesmo fantasiar e mentir. Sendo assim, até que ponto se pode

\footnotetext{
${ }^{14} \mathrm{O}$ exemplo do "enorme peixe" de Otto diz respeito aos fatos estarem sempre interligados. "E como se um enorme 'peixe' aparecesse na superfície da água somente com algumas partes suas e agora se tentasse classificar espécie e gênero analisando isoladamente o dorso, a ponta da cauda, depois uma cabeça a espirrar água para cima, em vez de reconhecer que se trata de membros interligados, os quais é necessário entender primeiro como um todo, antes de se entender suas partes" (OTTO, 2007, p.170).

${ }^{15}$ Paul Thompson (2002) aponta que apenas a expressão "história oral" é recente, porém, sua prática é tão antiga quanto a própria história. Verena Alberti, no seu Manual de História Oral (2005), lembra que Heródoto e Tucídides já utilizavam relatos e depoimentos para construir suas narrativas. Tomemos também como modelo o historiador francês Jules Michelet, historiador profissional francês de meados do século XIX, professor da École Normale, da Sorbonne, e do Collège de France e curador-chefe histórico dos arquivos Nacionais. Ao escrever a sua História da Revolução Francesa (1847-53), por nascer em Paris em 1798, menos de dez anos da queda de Bastilha, podia utilizar-se da própria memória. Para Michelet, os documentos escritos ocupavam apenas o lugar de mais uma dentre as diversas fontes existentes. "Evidentemente, Michelet tinha habilidade para escutar e para puxar pela língua de um informante. Possuía também ideias claras sobre em que áreas a evidência oral era mais, ou menos, confiável” (THOMPSON, 1992 p. 46).
} 
acreditar no que os entrevistados afirmam? A história oral oferece uma significativa contribuição para "o resgate da memória nacional”, como afirma Sônia Maria de Freitas (1992), no prefácio à edição Brasileira do livro de Thompson ${ }^{16}$. Para a autora, a história oral se caracteriza por dar voz a vários narradores diferentes. Dito isto, voltamos a tocar na questão da veracidade dos discursos:

\begin{abstract}
Um dos aspectos mais polêmicos das fontes orais diz respeito a sua credibilidade. Para alguns historiadores tradicionais os depoimentos orais são tidos como fontes subjetivas por nutrirem-se da memória individual, que às vezes pode ser falível e fantasiosa. No entanto, a subjetividade é um dado real em todas as fontes históricas, sejam elas orais, escritas ou visuais. O que interessa em história oral é saber por que o entrevistado foi seletivo, ou omisso, pois essa seletividade com certeza tem o seu significado (FREITAS, In: THOMPSON, 2002 p. 18).
\end{abstract}

A história oral é capaz de relevar novos campos de investigação ${ }^{17}$. De acordo com Thompson (1992), a utilização da voz humana tem a competência de trazer o passado ao presente de maneira imediata, pois as palavras são expressivas mesmo quando ditas de forma idiossincrática.

No desenrolar das duas práticas analisadas, as ações se igualam: ambas escolhem quem entrevistar e sobre o que perguntar; podem, por meio da entrevista, ter acesso a documentos escritos e fotográficos. "Os historiadores orais podem pensar agora como se eles próprios fossem editores: imaginar qual a evidência de que precisam, ir procurá-la e obtê-la". A história oral proporciona liberdade à significação cultural do documento escrito, "uma vez que a experiência de vida das pessoas de todo o tipo possa ser utilizada como matéria-prima, a história ganha nova dimensão" (THOMPSON, 1992 p. 25).

\title{
Relacionamento com as fontes
}

\footnotetext{
16 THOMPSON, Paul. A voz do passado, história oral. Rio de Janeiro: Paz e Terra, 1992. A relação de Paul Thompson com a história oral aconteceu na década de 60, momento o qual fez parte da equipe do Departamento de Sociologia da Universidade de Essex estudando a história social inglesa sem documentação e uma escassa literatura (THOMPSON, 2002 p. 15).

${ }^{17} \mathrm{O}$ primeiro trabalho organizado de história oral aconteceu em 1948. Foi nessa época que foi lançado, pelo professor Allan Nevis, o The Oral History Project, da Universidade de Colúmbia, que possui cerca de seis mil fitas gravadas, além das mais de 600 mil páginas de transcrição. Nas décadas de 1960 e 1970, foi constituída a Oral History Association (OHA) nos Estados Unidos. De acordo com Alberti, a propagação da história oral na década de 1970, que aconteceu na Europa e Estados Unidos, foi responsável pela implantação de diversas pesquisas e programas a partir do método. No Brasil, o Programa de História Oral do Cpdoc contou com duas tendências: a norte-americana (formação de banco de depoimentos orais sem pertencer necessariamente a um projeto de pesquisa) e a europeia (investigação científica) (ALBERTI, 2005). Encontramos, hoje, a história oral estabelecida em diversos outros países, tais como Grã-Bretanha, Itália, Alemanha, Canadá e França. No Brasil, "foram identificados 125 projetos de história oral em desenvolvimento, sendo que 49 individuais e 76 projetos institucionais" (FREITAS, In: THOMPSON, 1992 p. 16-17).
} 
Visto que a entrevista, o testemunho e, consequentemente, o relacionamento dos pesquisadores com as fontes estão presentes nas áreas das ciências humanas, ressalto a tese de Cremilda Medina de que o diálogo é a melhor maneira de atingir os limites da inter-relação. "Se quisermos aplacar a consciência profissional discuta-se a técnica da entrevista; se quisermos trabalhar pela comunicação humana, proponha-se o diálogo" (MEDINA, 2001 p. 5). Entretanto, ele surge especialmente conforme o grau de sensibilidade, ou seja, através do gesto, atitude corporal e olhar do entrevistado. O pesquisador, então, precisa enfrentar os desafios e utilizar a criatividade para quebrar barreiras e conseguir dialogar com suas fontes, tendo, inclusive, que escolher o local mais adequado para o encontro, já que este também é um fator que influencia a disposição do informante.

Tom Wolfe (2005) complementa ao recomendar que o entrevistador não restrinja as fontes a um questionamento, pois é preciso deixá-las livres e ouvi-las além do que é estipulado. Para ter sucesso numa entrevista, Thompson (1992) observa que é preciso habilidade. Os diferentes estilos existentes, desde uma conversa amigável até a maneira mais formal de perguntar, fazem com que os pesquisadores desenvolverem métodos variados de acordo com sua personalidade ${ }^{18}$.

Para Alberti (2005), a atenção destinada ao entrevistado é de grande importância, pois essa demonstração de interesse faz com que o informante sinta-se estimulado a falar. "Assim, deve-se procurar desviar o menos possível os olhos para o gravador ${ }^{19}$ ou para as anotações de apoio, e estar constantemente olhando para o entrevistado, certificando-o de que acompanhamos o que diz" (ALBERTI, 2005 p.114).

\section{Tempo presente}

No final dos anos 1970, ocorreram algumas mudanças da concepção da historiografia e da relação da sociedade com a sua história, emergindo assim a história do tempo presente. Isso se deu devido ao interesse pela temática da memória. O fim do século XX foi palco de

\footnotetext{
18 [...] desde os anos 1980, a entrevista (método sociológico), cuja técnica consiste na classificação, gravação, numeração, transcrição, é utilizada como fonte escrita, não só pelos historiadores, mas por arquivistas (em arquivos nacionais e em comitês de história em administrações públicas). Aprendendo a se servir dos aportes das ciências humanas, como a psicanálise, o historiador realiza uma melhor interação com a testemunha. Trabalhando com a noção de testemunho, os historiadores do presente descobrem os mecanismos da escuta, o papel do silêncio e a função das chamadas transferências e contratransferências (RODRIGUES, 2010, p. 6).

${ }^{19} \mathrm{Em}$ relação aos equipamentos utilizados no ato da entrevista, mesmo que seja de grande importância o uso do gravador para o tratamento do acervo, Thompson aconselha outra forma de contato: uma entrevista na qual nada esteja entre o entrevistado e entrevistador, pois há certo temor em ações como anotações e, mais ainda, com o uso do gravador. "[...] um entrevistador qualificado pode aprender a reter o suficiente das informações principais e das frases essenciais para lançá-las no papel logo depois, e fazer uma entrevista que valha a pena" (THOMPSON, 1992, p. 264).
} 
transformações que estabeleceram "formas de experiência que modificaram drástica e rapidamente as percepções sobre o tempo e o espaço, o que pode ser percebido em uma crescente musealização no cotidiano" (SILVA, 2009, p. 125).

Ciente de que a interpretação é causadora de indagações e discussões, Rodrigues (2010) considera a temporalidade como algo que sempre representou um desafio para a interpretação histórica. Passando a ser problematizada por ser um novo olhar para a prática historiografia, a história do tempo presente equivale a uma contemporaneidade histórica, ao período de uma experiência de vida. Experiência esta que é constituída por testemunhas e, como afirma Rodrigues, tem a "memória viva" com o objeto de sua história.

Para Enrique Serra Padrós (2004), a história do tempo presente é a história do nosso tempo, ou seja, do tempo de vida do pesquisador, que tem como abordagens captar a atualidade, a emergência das tendências, as novidades, e estabelecer uma vinculação que as interligam com o passado. Sônia Maria de Meneses Silva (2010) pondera uma produção de conhecimento histórico que se encontra fora do campo propriamente científico da História. Trata-se da ação dos meios de comunicação que, no final do século XX, vêm influenciando o campo da História. A autora considera que há "fazedores de história". "Além de produzir história, vender o passado tornou-se uma atividade estimulante, pois, o interesse quase obsessivo por ele, levou a uma verdadeira profusão na distribuição de obras e produtos que incentivaram e alimentam uma sede de história em nosso cotidiano" (SILVA, 2010, p. 134).

Ao analisar a ação dos meios de comunicação na produção dos sentidos sobre o passado e o presente e questionar o papel da história na contemporaneidade, Silva (2010) mostra que, enquanto os historiadores estão buscando estudar o presente, os jornalistas estão fazendo o caminho inverso.

\footnotetext{
Através da informação das bases, dos bancos de dados e da própria fabricação do "papel" que se pode alimentar quase à vontade no "doc", na pesquisa mais avançada e multiplicada junto aos correspondentes locais, da fabricação do dossiê em estilo news, da exibição da memória arquivada do jornal que dá consistência a seu propósito, pela fama também dos suplementos que ajudam a relativizar a atualidade e a refletir sobre ela, o exame da atualidade tornou-se uma crônica durável, tomou uma textura e uma espessura que o aproximam mais de um produto histórico (RIOUX In: CHAUVEAU; TÉTART, 1999, p. 123).
}

Sendo a história mutável, as interrogações sobre o presente não se limitam apenas aos campos, métodos e teorias, segundo Chauveau e Tétart (1999). O impacto dos acontecimentos e, consequentemente, a vontade de explicá-los, é um fator comum em diversas profissões. Entretanto, há fatores próprios aos jornalistas e historiadores: 


\begin{abstract}
Para os jornalistas, adiantaremos, entre outras razões, o papel da decomposição da imprensa nos anos 30 e o subsequente desejo de depor, desde 1945, um comentário mais rigoroso do presente, do imediato. Para os historiadores, trata-se, sobretudo, como dizíamos acima, da germinação de um pressuposto metodológico maior: a história não é somente o estudo do passado ela também pode ser, com um menor recuo e métodos particulares, o estudo do presente (CHAUVEAU; TÉTART, 1999 p. 15).
\end{abstract}

Um fator importante que está presente no trabalho do jornalista e do historiador do tempo presente é a grande variedade e quantidade de fontes. Para Padrós (2004), ao mesmo tempo em que tal fato é uma dificuldade, pelo pesquisador não ter tempo suficiente para trabalhar todas as fontes disponíveis, é também um privilégio, pois existe a possibilidade de recorrer a inúmeras fontes. Outra característica do tempo presente é a inconclusividade dos processos, o que torna a história do tempo presente um vasto campo de possibilidades, uma vez que o futuro encontra-se em aberto.

\title{
Considerações finais
}

Após a conclusão do presente estudo, foi possível verificar que enquanto o historiador oferece sentido às sociedades e períodos, o jornalista trabalha o desenrolar de acontecimentos relacionados a estes por meio da informação, produzindo, assim, cada um, continuidade, ao trabalho do outro. O historiador, através do grau de aprofundamento em seus trabalhos, favorável ao meio acadêmico, oferece fontes e dados completos ao jornalista. Bem como as publicações dos jornalistas servem como fonte de pesquisa para os historiadores.

Uma das principais diferenças da prática jornalística e a historiográfica está no momento da elaboração dos materiais. Enquanto os historiadores estão acostumados a dedicar mais tempo na produção de seus artigos, o jornalista está habituado com a rotina das redações, sempre ciente de que seu trabalho passará por uma grande cadeia organizacional. Salvo algumas exceções, como livro-reportagem, reportagens investigativas e outras que possibilitam uma investigação e estudo mais prolongado, o jornalista, normalmente, deve cumprir seu deadline.

Uma vez que o tempo na história do tempo presente é indeterminado e se baseia na preservação de rastros dos acontecimentos, na transmissão e no testemunho, este se caracteriza

por ser uma nova maneira de escrever a história. É por esta razão que tal metodologia se defronta com discussões já citadas na presente pesquisa, tais como a problemática que gira em torno da memória e da verdade, uma vez que estamos falando de um passado bem mais próximo do que sempre foi de praxe para os historiadores. 
Aliados aos demais fatores, o contato e a observação direta são ferramentas de extrema importância no trabalho do jornalista e do historiador devido ao fato de possibilitarem o aprofundamento na análise de campo das práticas através da captação da conduta de seu objeto, pois acarretam na situação de convivência. Dito isto e considerando as duas práticas como formações discursivas, estando sujeitas às condições e riscos semelhantes, tanto os historiadores como os jornalistas estão sujeitos a deixar que seu ponto de vista e seu lugar social interfiram no discurso o qual estão produzindo, pois não se pode evitar pertencer ao entorno histórico no qual está. Sendo assim é inevitável a convergência que gira em torno das duas profissões. (Artigo recebido em 05/12/2013, aprovado em 10/12/2013)

\section{Referências}

ALBERTI, Verena. Manual de história oral. 3. ed. Rio de Janeiro: Ed. FGV, 2005.

BENETTI, Marcia. Análise do Discurso em jornalismo: estudo de vozes e sentidos. In: LAGO, Cláudia; BENETTI, Marcia (org.). Metodologia de pesquisa em jornalismo. Petrópolis: Vozes, 2007.

BOSI, Ecléa. Memória e sociedade: lembranças de velhos. 3. ed. São Paulo: Cia das Letras, 1994.

CHARTIER, Roger. Inscrever e apagar: cultura escrita e literatura, séculos XI - XVIII. São Paulo: UNESP, 2007.

CHAUVEAU, Agnes; TÉTART, Philippe. Questões para a história do presente. Tradução Ilka Stern Cohen. SP: EDUSC, 1999.

FOUCAULT, Michel. A Arqueologia do saber. 6. ed. Rio de Janeiro: Forense Universitaria, 2002.

FOUCAULT, Michel. A ordem do discurso: aula inaugural no Collège de France, pronunciada em 2 de dezembro de 1970. 19. ed. São Paulo: Loyola, 2009.

GINZBURG, Carlo. O Fio e os Rastros. O inquisidor como antropólogo. SP: Cia das Letras, 2007.

HUNT, Lynn. A invenção dos direitos humanos, uma história. São Paulo: Companhia das Letras, 2009.

LAGE, Nilson. Estrutura da notícia. São Paulo: Ática, 2000.

LAPLANTINE, François. Aprender Antropologia. São Paulo: Editora Brasiliense, 1988.

LE GOFF, Jacques. CHARTIER, Roger. REVEL, Jacques. A história nova. 4.ed. São Paulo: Martins Fontes, 1998. 
MEDINA, Cremilda de Araújo. Entrevista: o diálogo possível. São Paulo: Ática, 2001.

OTTO, Rudolf. O Sagrado. Petrópolis: Vozes, 20072007.

PADRÓS, Enrique Serra. Os desafios da produção do conhecimento histórico sob a perspectiva do Tempo Presente. Anos 90. Revista do PPGH-UFRGS. 2004, vol.11.

REIS, Jose Carlos. História e Teoria. História e verdade: posições. Rio de Janeiro: FGV, 2003. RIOUX, Hean Pierre. In: CHAUVEAU, Agnes; TÉTART, Philippe. Questões para a história do presente. Tradução Ilka Stern Cohen. SP: EDUSC, 1999.

RODRIGUES, Helenice. História do tempo presente: problemática das fontes. Acesso em 03/11/2010. Disponível em www.poshistoria.ufpr.br/fonteshist/Helenice.pdf

SANTOS, Rafael José. Antropologia para quem não vai ser antropólogo. Porto Alegre: Tomo Editora, 2005.

SILVA, Sônia Maria de Meneses. A “musealização" do presente: Mídia, Memória e Esquecimento, questões para pensar a história hoje. Acesso em 05/11/2010. Disponível em www.poshistoria.ufpr.br/fonteshist/Helenice.pdf

THOMPSON, Paul. A voz do Passado. Rio de Janeiro: Paz e Terra, 1992.

WOLFE, Tom. Radical Chique e o Novo Jornalismo. São Paulo: Companhia das Letras, 2005. 